\title{
Pili Torti as a Sign of Eyebrow Involvement in Frontal Fibrosing Alopecia
}

\author{
Bruno Ferrari ${ }^{a}$ Colombina Vincenzi ${ }^{b}$ Antonella Tosti ${ }^{c}$ \\ a Dermatology Service, Hospital Ramos Mejía, Universidad de Buenos Aires, Buenos Aires, Argentina; \\ ${ }^{b}$ Department of Dermatology, University of Bologna, Bologna, Italy; ${ }^{C}$ Dr. Phillip Frost Department of \\ Dermatology and Cutaneous Surgery, University of Miami Miller School of Medicine, Miami, FL, USA
}

\section{Established Facts}

- Trichoscopy findings of the eyebrows in frontal fibrosing alopecia patients include dystrophic hair, whitish areas with absence of follicular openings, and eyebrow regrowth in different directions.

\section{Novel Insights}

- Pili torti, which are flattened hair shafts that are twisted at irregular intervals along its long axis, may be present on frontal fibrosing alopecia eyebrow trichoscopy. This is a sign of fibrosis and would predict poor response to treatment with intralesional steroids.

\section{Keywords}

Pili torti · Alopecia · Frontal fibrosing alopecia

\section{Abstract}

Frontal fibrosing alopecia (FFA) is a disease characterized by progressive band-like scarring alopecia involving the frontotemporal hairline and eyebrow hair loss. It affects mainly postmenopausal women. Trichoscopy features of FFA include absence of vellus hair, perifollicular erythema and scaling (peripilar casts), and absence of follicular openings. Trichoscopy of eyebrows in FFA patients shows tapered and broken hair, absence of follicular openings, black dots, and hair growing in different directions. We report a case of FFA with numerous pili torti in the eyebrows.

(c) 2019 S. Karger AG, Basel

\section{Introduction}

Frontal fibrosing alopecia (FFA) is a scarring alopecia which is characterized by progressive recession of the frontotemporal hairline [1-4], sideburns, and alopecia of the eyebrows. It affects mainly postmenopausal women [3]. An abrupt interruption of the hairline, with the absence of vellus hair is the main key for diagnosis on trichoscopy [1]. Other trichoscopy findings on the scalp are perifollicular erythema and scaling, absence of follicular openings, black dots, and pili torti [1-3]. Trichoscopy of the eyebrows in FFA has recently been delineated. It includes dystrophic hair and whitish areas with absence of follicular openings $[3,4]$. Eyebrow regrowth in different directions is very typical [5]. Tapered hair, broken

\section{KARGER}

(c) 2019 S. Karger AG, Basel

E-Mail karger@karger.com

www.karger.com/sad
Bruno Ferrari

Dermatology Service, Hospital Ramos Mejía Urquiza 609

Buenos Aires, CABA C1221ADC (Argentina)

E-Mail brunoferraripiel@gmail.com 


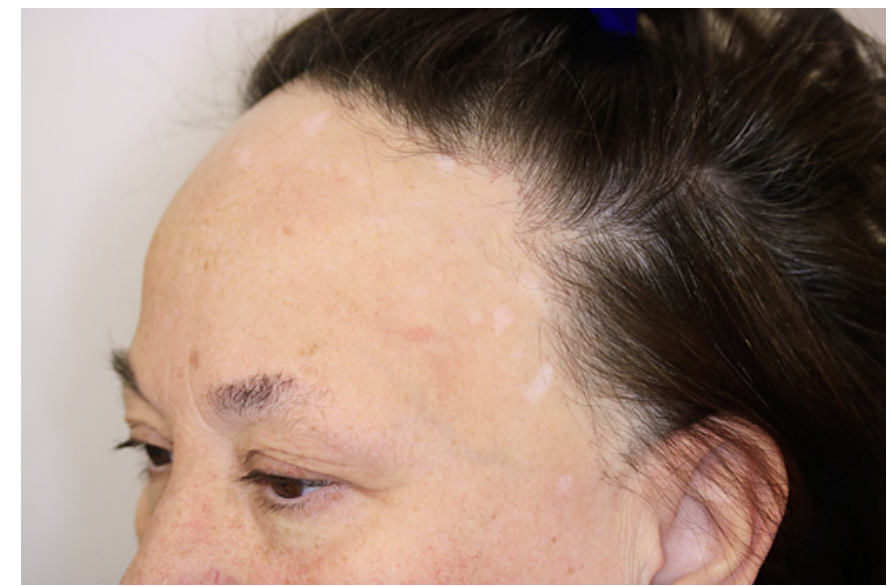

Fig. 1. Recession of the frontal hairline and sideburns. Loss of the lateral eyebrows. Scattered white macules on her forehead.

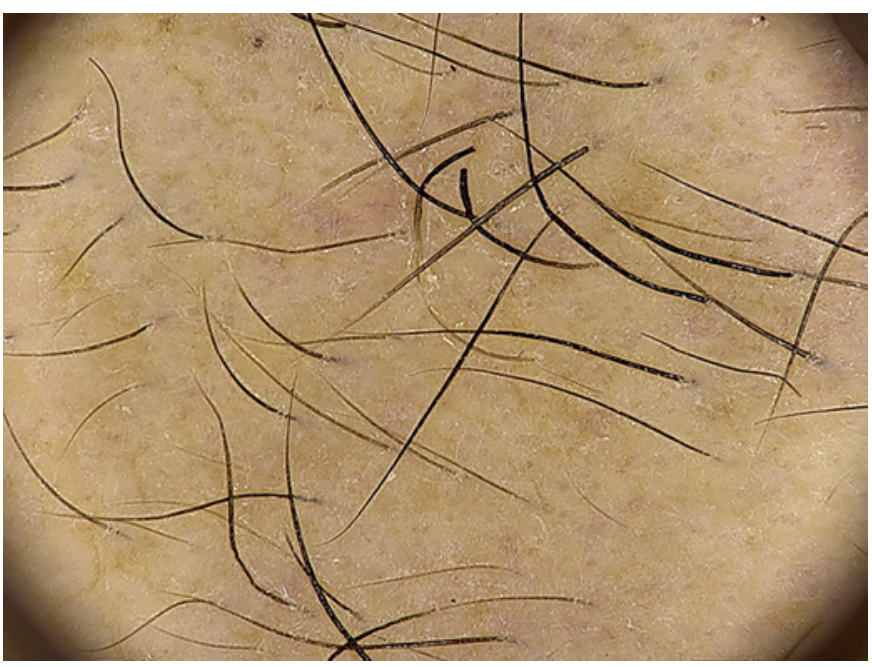

Fig. 2. Eyebrow dermoscopy revealed black dots, hair growing in different directions, and numerous pili torti.

hair, black and yellow dots may be observed in FFA eyebrows, but less frequently than in alopecia areata $[3,5]$. We report a female patient with FFA with numerous pili torti in the eyebrows.

\section{Case Presentation}

A 58-year-old Caucasian female presented with symmetrical progressive recession of the frontal hairline and sideburns which had started 3 years before and recent loss of the lateral eyebrows with intense itch. She also presented scattered white macules on her forehead (Fig. 1). Trichoscopy of the frontotemporal scalp showed loss of vellus hair, prominent peripilar casts, and absence of follicular openings.
Dermoscopy of her eyebrows revealed black dots, hair growing in different directions, and presence of numerous pili torti (Fig. 2). A 2-mm biopsy from the affected hairline confirmed the diagnosis of FFA. The eyebrows were treated with intralesional triamcinolone injections at a dilution of $2.5 \mathrm{mg} / \mathrm{mL}$ every 6 weeks with no clinical improvement after 3 sessions.

\section{Discussion/Conclusion}

Madarosis (partial or complete eyebrow loss) is observed in most patients with FFA and may precede scalp alopecia in more than a third of the cases $[5,6]$. Trichoscopy of the eyebrows is very useful when they are the unique localization of the disease and in unclear cases [3, 5]. Typical FFA scalp trichoscopy findings are not usually observed in the eyebrows $[4,5]$. The main features in this location are dystrophic hair and whitish areas with absence of follicular openings [3-5] but presence of pinpoint dots, which are eccrine duct openings [5].

Recently, Waśkiel-Burnat et al. [5] reported hair growing in different directions as a sign of FFA in the eyebrows. They hypothesized that it reflects a fibrosing process [5]. Less frequently, typical alopecia areata trichoscopy findings, such as tapered hair, broken hair, black and yellow dots, may be observed in the eyebrows of patients with FFA [3-5]. Nevertheless, in this disease, follicular openings tend to be more reddish or greyish $[5,7]$.

Pili torti is defined as flattened hair shafts which are twisted at irregular intervals along its long axis $[1,8]$. It may be inherited or acquired, and it could affect scalp hair, eyelashes, eyebrows, and axillary hair. A few pili torti are a common finding on the scalp of cicatricial alopecia patients, including FFA [9]. However, to the best of our knowledge, this is the first case in the literature presenting pili torti on eyebrow trichoscopy. This is another sign of fibrosis, and, possibly, it explains the poor response that our patient showed to treatment with intralesional steroids.

\section{Statement of Ethics}

The authors of the present article state that the subject has given her written informed consent to publish her case (including publication of images).

\section{Disclosure Statement}

The authors have no conflicts of interest to declare. 


\section{Funding Sources}

The authors have not received any funding for their study or the preparation of data or manuscript.

\section{Author Contributions}

Bruno Ferrari: substantial contributions to the conception or design of the work; or the acquisition, analysis, or interpretation of data for the work. Drafting the work or revising it critically for important intellectual content. Agreement to be accountable for all aspects of the work in ensuring that questions related to the accuracy or integrity of any part of the work are appropriately investigated and resolved.

Colombina Vincenzi: substantial contributions to the conception or design of the work; or the acquisition, analysis, or interpretation of data for the work.

Antonella Tosti: substantial contributions to the conception or design of the work; or the acquisition, analysis, or interpretation of data for the work. Drafting the work or revising it critically for important intellectual content. Final approval of the version to be published. Agreement to be accountable for all aspects of the work in ensuring that questions related to the accuracy or integrity of any part of the work are appropriately investigated and resolved.

\section{References}

1 Lacarrubba F, Micali G, Tosti A. Scalp dermoscopy or trichoscopy. In: Ioannides D, Tosti A, editors. Alopecias - practical evaluation and management. Curr Probl Dermatol. Basel: Karger; 2015. vol. 47, p. 21-32.

2 Pirmez R, Tosti A. Trichoscopy Tips. Dermatol Clin. 2018 Oct;36(4):413-20.

3 Iorizzo M, Tosti A. Frontal Fibrosing Alopecia: An Update on Pathogenesis, Diagnosis, and Treatment. Am J Clin Dermatol. 2019 Jun;20(3):379-90.
4 Anzai A, Donati A, Valente NY, Romiti R, Tosti A. Isolated eyebrow loss in frontal fibrosing alopecia: relevance of early diagnosis and treatment. Br J Dermatol. 2016 Nov; 175(5):1099-101.

5 Waśkiel-Burnat A, Rakowska A, Kurzeja M, Czuwara J, Sikora M, Olszewska M, et al. The value of dermoscopy in diagnosing eyebrow loss in patients with alopecia areata and frontal fibrosing alopecia. J Eur Acad Dermatol Venereol. 2019 Jan;33(1):213-9.

6 Vañó-Galván S, Molina-Ruiz AM, SerranoFalcón C, Arias-Santiago S, Rodrigues-Barata AR, Garnacho-Saucedo G, et al. Frontal fibrosing alopecia: a multicenter review of 355 patients. J Am Acad Dermatol. 2014 Apr; 70(4):670-8.
7 Rakowska A, Slowinska M, Kowalska-Oledzka E, Warszawik O, Czuwara J, Olszewska M, et al. Trichoscopy of cicatricial alopecia. J Drugs Dermatol. 2012 Jun;11(6):753-8.

8 Rudnicka L, Olszewska M, Waśkiel A, Rakowska A. Trichoscopy in Hair Shaft Disorders. Dermatol Clin. 2018 Oct;36(4):421-30.

9 Sakamoto F, Ito M, Saito R. Ultrastructural study of acquired pili torti-like hair defects accompanying pseudopelade. J Dermatol. 2002 Apr;29(4):197-201. 